\title{
MORPHOLOGICAL STUDY OF DORSAL LINGUAL PAPILLAE OF THE GREEN TOAD (BUFO BUFO)
}

\author{
N. GOODARZI ${ }^{1}$, M. AZARHOOSH ${ }^{2} \&$ GH. AKBARI ${ }^{3}$ \\ ${ }^{1}$ Department of Basic Sciences, Faculty of Veterinary Medicine, Razi University, \\ Kermanshah, Iran; ${ }^{2}$ Faculty of Veterinary Medicine, Razi University, Kermanshah, \\ Iran; ${ }^{3}$ Department of Basic Sciences, Faculty of Veterinary Medicine, \\ University of Tabriz, Tabriz, Iran
}

\section{Summary}

Goodarzi, N., M. Azarhoosh \& Gh. Akbari, 2018. Morphological study of dorsal lingual papillae of the green toad (Bufo bufo). Bulg. J. Vet. Med., 21, No 2, 224-231.

The present study investigated the structure of the dorsal lingual surface tongue of the toad, Bufo bufo habitat in the west of Iran. The tongue of the toad contains two types of lingual papillae; fungiform papillae and filiform papillae. The fungiform papillae are usually scattered among the filiform papillae and are believed to function in gustation and in the secretion of salivary fluid. Light microscopic observations showed that a non-keratinised pseudo stratified columnar epithelium with ciliated cells lined the lingual papillae. Scanning electron microscopic examinations revealed that a taste disc (honeycomb) was located at the apical surface of each fungiform papillae. The surface of the disc had a latticework pattern. However, no ciliated cells were observed in the surrounding area of the sensory disc. As a result, the morphology of the lingual epithelium of the Bufo Bufo is species-specific. However, it is somewhat similar to that of Bufo japonicus and distinctly different from that of Bufo regularis.

Key words: green toad, lingual papillae, morphology

The tongue plays a principal role in feeding mechanism, together with other organs within and near the oral cavity. Most adult amphibians have a tongue (Helff, 1929), as do all known reptiles, birds and mammals. Amphibians usually live in and around freshwater, and the surface of the oral cavity around the tongue is wet. Even on land, amphibians are not generally exposed to extremely dry conditions, and, consistently, no keratinisation is found in the amphibian lingual epithelium (Iwasaki \& Kobayashi, 1989; Iwasaki et al., 1989a,b).

The tongues of amphibians should contribute both to catch food and to moisten it (Graziadei \& DeHan, 1971; Zylberberg, 1977). A large part of the lingual epithelium consists of cells with secretory granules. The material secreted by these 
granules probably play the same role as saliva.

Among amphibians, toads have been adapted to a comparatively dry habitat and they can live in areas away from ponds and rivers for extended periods. Owning to this capacity, the lingual epithelium consists partly of cells without secretory granules (Frye, 1991). There are many reports investigating the fine structure of the dorsal lingual epithelium in various species of amphibians including Bufo regularis (Elsheikh et al., 2013), Bullfrog (Iwasaki \& Sakata, 1985), Japanese toad (Iwasaki \& Kobayashi 1988), crab-eating frog (Iwasaki \& Wanichanon, 1993), Runa Rugoza (Iwasaki \& Wanichanon, 1991), Pelobates fuscus (Zuwala, 2002), Alpine newt (Zuwala \& Jakubowsky, 2007), Spotted salamander (Zuwała \& Jakubowski, 2001), Rana ridibunda (Esrefoglu et al., 2000) and Rana catesbeiana (Guiraldelli et al., 2011). This study was conducted to examine the morphological characteristics of the dorsal lingual papillae at the level of light and scanning electron microscope in the green toad, Bufo bufo living in the west of Iran and to compare these features with observations in various toads species related to their habitats.

Five adult toads, Bufo bufo were captured from rivers around the city of Kermanshah, the western province of Iran. Kermanshah province is located at latitude $33^{\circ} 35^{\prime} \mathrm{N}$ and longitude $45^{\circ} 47^{\prime} \mathrm{E}$ with altitude $1350 \mathrm{~m}$ above sea level. The specimens were euthanised with chloroform inhalation and the tongues were dissected from the mandible. For light microscopic observations, two specimens were fixed in $10 \%$ neutral formaldehyde for seven days. They were embedded in paraffin, serially sectioned at $5 \mu \mathrm{m}$ thickness and stained with haematoxylin and eosin. For electron microscopy the tongues after removal were fixed in $2.5 \%$ glutaraldehyde in $0.1 \mathrm{M}$ cacodylate buffer at $4{ }^{\circ} \mathrm{C}$ for $24 \mathrm{~h}$. After rinsing in cold $0.1 \mathrm{M}$ cacodylate buffer, samples were then post-fixed with $1 \%$ osmium tetroxide solution at $4{ }^{\circ} \mathrm{C}$. Following dehydration in ascending concentration of ethanol (50-99.8\%) at room temperature, the samples were dried at critical point in carbon dioxide, mounted on the aluminium stubs and coated with gold palladium in a sputtering device. The specimens were examined and photographed at various angles under a scanning electron microscope (VEGA, TESCAN, Brno, Czech Republic) at accelerating voltages of $15 \mathrm{kV}$.

The tongue of green toad, Bufo bufo was approximately $7 \mathrm{~cm}$ in length and 0.5 $\mathrm{cm}$ in width. At light microscope level, the lingual mucosa was covered by a nonkeratinised pseudo-stratified columnar epithelium whose apical cells were ciliated. Two types of lingual papillae namely the filiform and fungiform papillae were observed (Fig. 1). Each papilla was composed of the lingual epithelium and a core of lamina propria and no taste buds were seen within them. The epithelium that formed the upper part of the filiform papillae was thicker than that forming the basal part. The former was composed of stratified columnar and/or cuboidal cells, whereas the latter - of simple columnar cells. Just beneath the lingual epithelium, the connective tissue of lamina propria had a network pattern and contained the bundles of striated muscles and its strands penetrated the center of each lingual papillae (Fig. 2).

At scanning electron microscope level, the filiform papillae were compactly distributed all over the dorsal lingual surface and fungiform papillae were scattered between them (Fig. 3a,b). A taste disc 


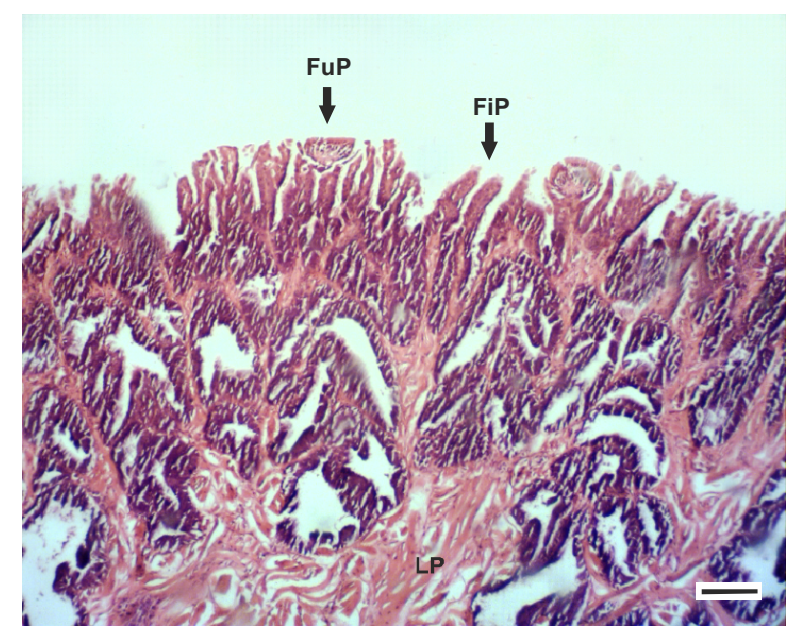

Fig. 1. A transverse section of Bufo bufo tongue showing filiform papillae (FiP), fungiform papillae (FuP) and lamina propria (LP) with muscular fibres (H \& E, bar $=200 \mu \mathrm{m})$.

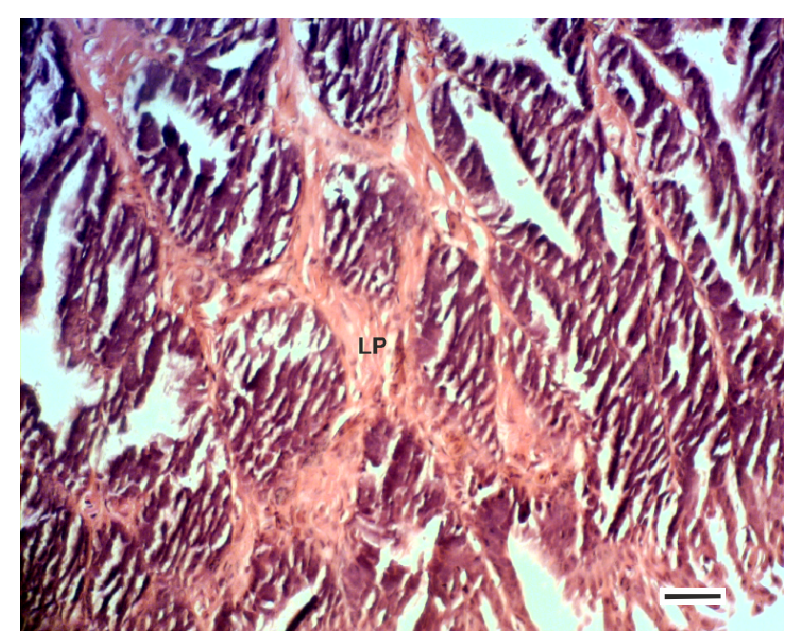

Fig. 2. A transverse section of Bufo bufo tongue showing network pattern of lamina propria (H \& E., bar $=100 \mu \mathrm{m})$.

(honeycomb) was located at the apical surface of each fungiform papillae. The surface of the disc had a latticework pattern which reflected the boundaries of the cells on the surface of the papilla (Fig. 4). The superficial layer of the taste disc was slightly convex and covered by a thick layer of mucous cells containing surfactant like material. Most of the surface was formed by the mucous cells. The irregular pattern of microridges on the free surface of mucous cell could be recognised (Fig. 5).

Results from the comparative studies of the lingual dorsal epithelium in different amphibians species would provide the 

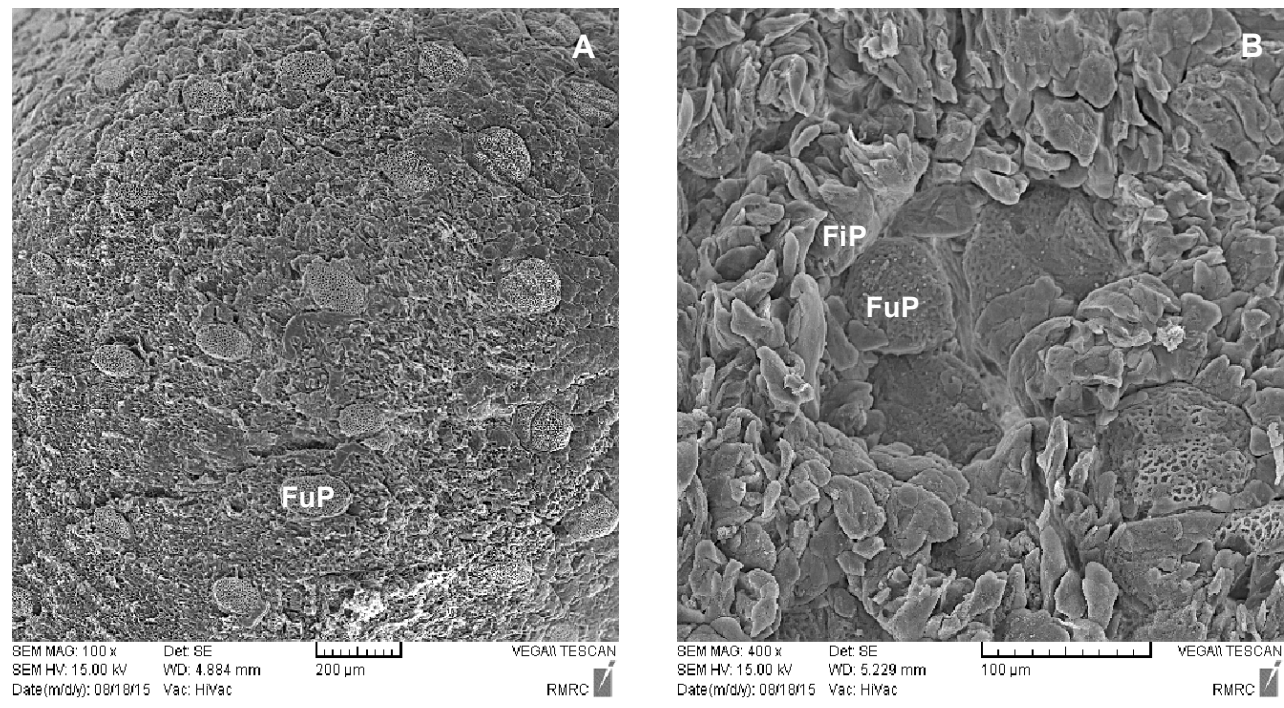

Fig. 3. Scanning electron micrograph of the dorsal lingual surface of Bufo bufo with fungiform papillae (FuP) distributed among filiform papillae (FiP) at two different magnifications.

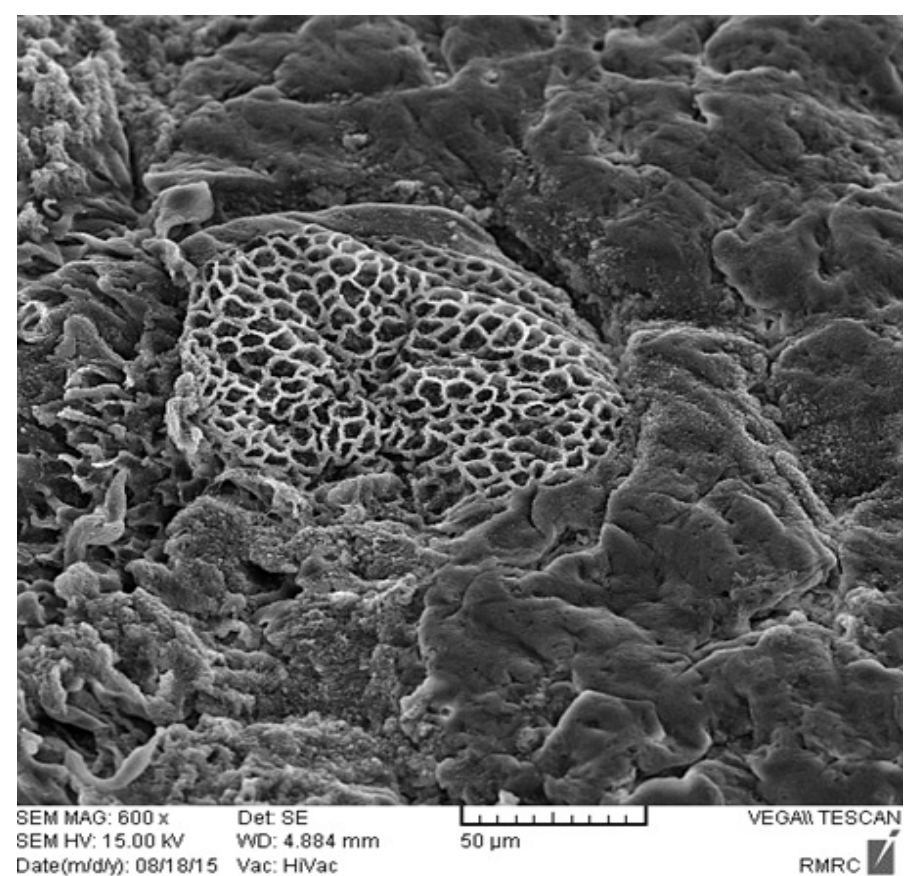

Fig. 4. Scanning electron micrograph of the fungiform papilla showing latticework structure of sensory disc on its the dorsal surface at higher magnification. 


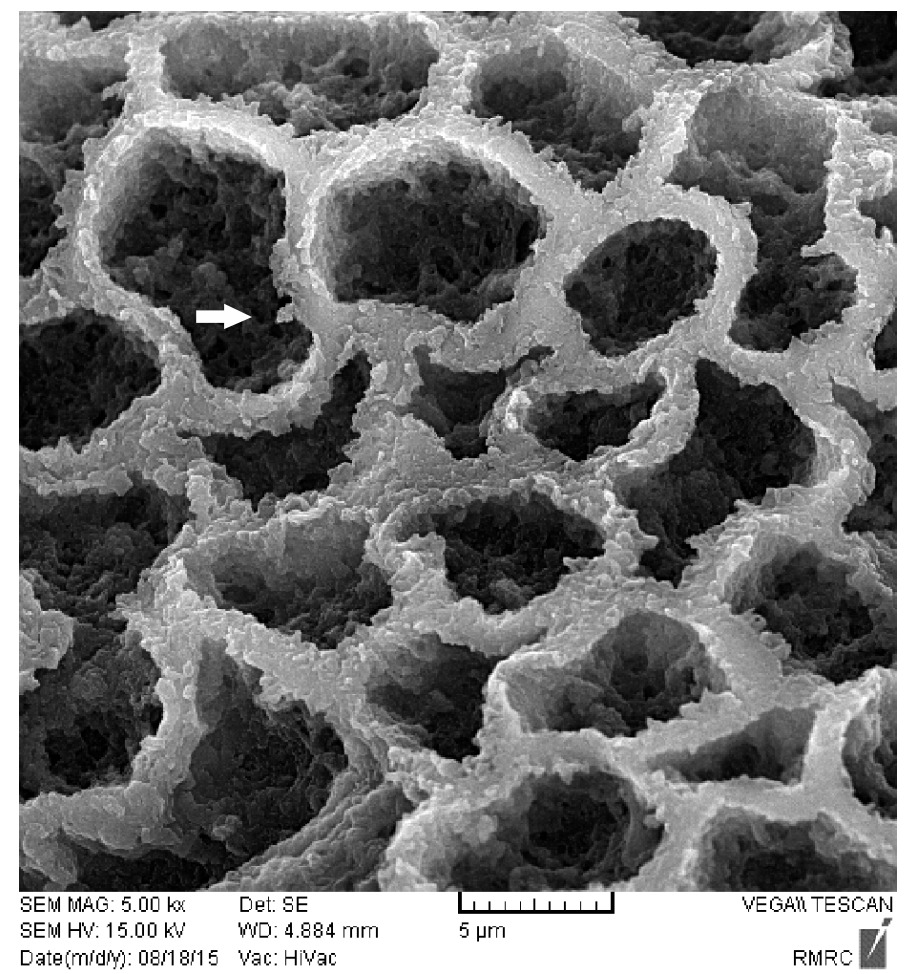

Fig. 5. Scanning electron micrograph of the sensory disc showing microridge (arrow) at higher magnification.

opportunity to examine the characteristics of this epithelium in terms of both function and phylogeny. The taste buds are common gustatory organs which are present throughout the entire life-span of most vertebrates. It is well known that taste buds are replaced by taste discs or sensory discs on the fungiform papillae during metamorphosis in anurans (Iwasaki \& Wanichanon, 1993; Zuwala \& Jakubowski, 1991).

The critical criterion used to distinguish taste buds from taste discs was the size of the organ. Both taste buds and taste discs fulfill similar chemoreceptive functions. However, there are clear morphological differences between these two kinds of organs, mainly in the non-sensory epithelial components which are differen- tiated into several kinds of cells (often named ''associate cell', and including mucous cells and wing cells). The broad sensory area in taste discs is the consequence of the large size of the mucous cells (Iwasaki, 2002).

The present work revealed that the surface of the sensory discs in Bufo bufo tongue is covered with a honeycomb array of cell surfaces, which originate from the non-gustatory, supporting cells. Similar results were reported in Bufo japonicus (Iwasaki \& Kobayashi, 1988), R. catesbeiana (Iwasaki \& Sakata, 1985) and $R$. cancrivora (Iwasaki \& Wanichanon, 1993). It has been reported that most of the surface of sensory discs in $R$. pipiens, $R$. esculenta and $R$. temporaria are covered extensively with microvilli (During \& 
Andres, 1976; Graziadei \& DeHan, 1971). However, the sensory discs of $R$. catesbeiana and Hyla arborea reportedly have cytoplasmic ridges and interspersed cells with microvilli (Jaeger \& Hillman, 1976). Unlike B. regularis (Elsheikh et al., 2013) and B. japonicus (Iwasaki \& Kobayashi, 1988 ) no ciliated cells were presented on the surface of the honeycomb in the $B$. bufo tongue. However, it has been reported that ciliated cells are absent from the fungiform papillae of members of the Bufonidae (Jasinski, 1979). With respect to function, the honeycomb structure may play a role in the retention of water and mucus on the surface of the sensory disc. Similar to those observed in B. japonicus (Iwasaki \& Kobayashi, 1988) and Bombina orientalis (Witt, 1993), the ciliated cells around the sensory disc were absent in the $B$. bufo, while these cells were seen in B. regularis (Elsheikh et al., 2013), $R$. catesbeiana (Guiraldelli et al., 2011) and $R$. cancrivora (Iwasaki \& Wanichanon, 1993). It should be noted that unlike B. japonicus (Iwasaki \& Kobayashi, 1988 ) and in B. regularis (Elsheikh et al., 2013), in the present work of $B$. bufo, the microvilli were presented on the fungiform papillae at light microscope level.

The filiform papilae of $B$. bufo were similar to those of $R$. catesbeiana (Guiraldelli et al., 2011) and $R$. rugosa (Iwasaki \& Wanichanon, 1991), but significantly different from those of $B$. japonicus (Iwasaki \& Kobayashi, 1988) in which the epithelium forms many ridge-like papillae and in B. regularis (Elsheikh et al., 2013) fork-shaped papillae were reported. Gonzales (2002) in a study, showed that the filiform papillae in B. marinus were covered by a bistratified epithelium which consisted of a basal layer of dendritic cells and an upper surface layer, consisting of numerous seromucous secretory cells, dendritic cells apical processes, and some goblet cell-like and ciliated cells. Jasinski (1979) previously revealed that the common toad possesses a tongue lacking filiform papillae on its dorsal surface.

Observations published by a number of researchers indicate that the dimension of the taste disk in various amphibian species differ to a considerable extent. The wide diversification in the diameter of taste disc also indicate that this parameter cannot be used as a principle one when categorising various types of sensory organs, i.e. taste disks and taste buds ( $\mathrm{Zu}-$ wala, 2002).

The common toads have adapted to a comparatively dry habitat and they can live in areas away from ponds and rivers for extended periods. Reflecting this capacity, the lingual epithelium consists partly of cells without secretory granules, especially on the apical side that is exposed to dry conditions. The separation of the tongue from the salivary glands is more conspicuous in terrestrial reptiles, birds and mammals (Iwasaki, 2002).

Overall, the findings of the present study indicate that the morphology of the lingual epithelium of the $B$. bufo is species-specific. However it is somewhat similar to that of $B$. japonicus and distinct from those of $B$. regularis and common toad described by Jasinski (1979). The subject of this study lives in West Iran with a mountainous climate and average temperature above $22^{\circ} \mathrm{C}$ in the hottest months and seems to be adapted to different mechanisms of food recognition and capture of prey. The similarity of taste disc between species seems to shows the independence of structural organisation from the respective environment. Nevertheless, the histochemical taste disc properties should be investigated to provide more precise data on gustatory functions. 


\section{ACKNOWLEDGEMENTS}

The authors wish to thank Miss. Khedmatgozar Dolati for her valuable assistance in preparing photographs.

\section{REFERENCES}

During, M. V. \& K. H. Andres, 1976. The ultrastructure of taste and touch receptors of the frog's taste organ. Cell and Tissue Research, 165, 185-198.

Elsheikh, E. H, K. E. Atta \& S. A. AlZahaby, 2013. Comparative study on the tongue of Bufo regularis and Chalcides ocellatus in relation to their habitats. Journal of Basic and Applied Zoology, 66,131-138.

Esrefoglu, M., A. Temelli \& M. Esrefoglu, 2000. Fine structure of the dorsal lingual epithelium of the frog, Rana ridibunda. Turgut Ozal Tip Merkezi Dergisi, 7, 67-72.

Frye, F. L., 1991. Reptile Care - an Atlas of Diseases and Treatment. Neptune: T.F.H. Publications, Inc.

Gonzales, E., 2002. New observations on the structure of the lingual filiform papillae epithelium of the toad Bufo marinus L.: Light and transmission electron microscopy study. Acta Cientifica Venezolana, 52, 283-291.

Graziadei, P. P. C. \& R. S. DeHan, 1971. The ultrastructure of frog's taste organ. Acta Anatomica, 80, 563-603.

Guiraldelli, M. F., R. A. Lopes, M. A. Sala \& T. R. V. P. Lopes, 2011. Morphological, histological and histochemical study of the lining and glandular epithelium of the tongue of the Bull frog Rana catesbeiana. International Journal of Morphology, 29, 226-233.

Helff, O. M., 1929. Studies on amphibian metamorphosis. IV. Growth and differentiation of anuran tongue during metamorphosis. Physiological Zoology, 2, 334341.
Iwasaki, S. \& K. Sakata, 1985. Fine structure of the lingual dorsal surface of the bullfrog. Okajimas Folia Anatomica Japonica, 61, 437-450.

Iwasaki, S. \& K. Kobayashi, 1988. Fine structure of the dorsal tongue surface in the Japanese toad, Bufo japonicus (Anura, Bufonidae). Zoological Science, 5, 331-336.

Iwasaki, S. \& K. Kobayashi, 1989. Fine structure of the lingual dorsal epithelium in the bullfrog, Rana catesbeiana. Zoological Science, 6, 259-267.

Iwasaki, S., K. Miyata \& K. Kobayashi, 1989a. Fine structures of the filiform papillar epithelium in the tongue of the frog, Rana nigromaculata. Zoological Science, 5, 61-68.

Iwasaki, S., K. Miyata \& K. Kobayashi, $1989 \mathrm{~b}$. Fine structures of the lingual dorsal epithelium of the Japanese toad, Bufo japonicus (Anura, Bufonidae). Zoological Science, 6, 681-689.

Iwasaki, S. \& C. Wanichanon, 1991. Fine structure of the dorsal lingual epithelium of the frog, Rana rugoza. Tissue and Cell, 23, 385-391.

Iwasaki, S. \& C. Wanichanon, 1993. An ultrastructural study of the dorsal lingual epithelium of the crab-eating frog, Rana cancrivora. Journal of Morphology, 215, 89 100.

Iwasaki, S., 2002. Evolution of the structure and function of the vertebrate tongue. Journal of Anatomy, 201, 1-13.

Jaeger, C. B. \& D. E. Hillman, 1976. Morphology of gustatory organ. In: Frog Neurobiology, eds R. Linal \& W. Precht, Springer-Verlag, Berlin, pp. 588-606.

Jasinski, A., 1979. Light and scanning microscopy of the tongue and its gustatory organs in the common toad, Bufo bufo (L.). Zeitschrift für Mikroskopisch-Anatomische Forschung, 93, 465-476.

Zuwala, K. \& M. Jakubowski, M, 1991. Development of taste organs in Rana temporaria: Transmission and scanning micro- 
scopic study. Anatomy and Embryology, 184, 363-369.

Zuwała, K. \& M. Jakubowski, 2001. Two types of taste organs (SEM, TEM) in the development of the spotted salamander Salamandra salamandra. Anatomy and Embryology, 204, 413-420.

Zuwala, K., 2002. Development of the tongue and taste disks in Pelobates fuscus. Folia Biologica, 50, 165-172.

Zuwala, K. \& M. Jakubowsky, 2007. Structural diversification of the gustatory organs during metamorphosis in the alpine newt Triturus alpestris. Journal of Anatomy, 211, 371-375.

Zylberberg, L., 1977. Histochemistry and ultrastructure of amphibian lingual glands and phylogenetic relations. Histochemical Journal, 9, 505-520.
Witt, M., 1993. Ultrastructure of the taste disc in the red-bellied toad Bombina orientalis (Discoglossidae, Salientia). Cell and Tissue Research, 272, 59-70.

Paper received 05.04.2016; accepted for publication 10.06.2016

\section{Correspondence:}

N. Goodarzi

Department of Basic Science,

Faculty of Veterinary Medicine,

Razi University, Resalat Bvld,

Kermanshah, Iran,

tel: +988338322599,

email: n.goodarzi@razi.ac.ir 